\title{
AORTIC VALVE REPLACEMENT WITH AN ANOMALOUS LEFT CIRCUMFLEX CORONARY ARTERY ENCIRCLING THE AORTIC ANULUS
}

\author{
Raja M. Flores, MD, and John G. Byrne, MD, Boston, Mass
}

Anomalous origin of the coronary arteries is usually an incidental finding. However, in patients undergoing routine aortic valve replacement, their presence can significantly complicate the procedure. If present, it is imperative that the precise anatomy is clearly identified and the required procedure modified to avoid injury to these vessels. In this report we document the first preoperative identification and successful management of this anomaly before aortic valve replacement.

Clinical summary. A 78-year-old woman was admitted with syncope. An echocardiogram revealed an aortic valve area of $0.7 \mathrm{~cm}^{2}$. Coronary angiography demonstrated no atherosclerotic disease; however, an anomalous left circumflex coronary artery originated from the right coronary sinus and coursed behind the aortic anulus before traveling into the atrioventricular groove (Fig 1).

An aortic valve replacement was performed through a median sternotomy. Aortic cannulation was performed through the aortic arch, and venous cannulation was performed through the right atrium. The patient was cooled to $28^{\circ} \mathrm{C}$, and myocardial protection was obtained by antegrade and retrograde cold blood potassium cardioplegia. An oblique aortotomy was performed, and a heavily calcified trileaflet

From the Division of Cardiac Surgery, Brigham and Women's Hospital, Boston, Mass.

Received for publication June 21, 2000; accepted for publication July 12, 2000.

Address for reprints: John G. Byrne, MD, Division of Cardiac Surgery, Brigham and Women's Hospital, 75 Francis St, Boston MA 02115 (E-mail: JBYRNE@PARTNERS.ORG).

J Thorac Cardiovasc Surg 2001;121:396-7

Copyright (C) 2001 by The American Association for Thoracic Surgery

$0022-5223 / 2001 \$ 35.00+0 \quad \mathbf{1 2 / 5 4 / 1 1 0 1 7 9}$

doi: $10.1067 / \mathrm{mtc} .2001 .110179$ aortic valve was excised. After this, attention was then turned to the anomalous left coronary artery. The anomalous left circumflex coronary artery originated from the right coronary ostia and traveled along the commissure between the noncoronary and left coronary cusps (Fig 2). The artery was sharply dissected free from the posterior aortic anulus until its course was identified in the atrioventricular groove (Fig 3). Once the coronary artery was believed to be completely free from the aortic anulus, the aortic sutures were placed into the anulus. The patient had a very small habitus, as well as a very small aortic anulus, and a No 19 St Jude Medical valve (St Jude Medical, Inc, St Paul, Minn) was placed. The patient did well postoperatively and was discharged home on the sixth postoperative day.

Discussion. Coronary angiography played a pivotal role in identifying this anomaly, thereby allowing a well-planned surgical approach. Although coronary angiography is standard in elderly patients with valvular disease, it is not standard in younger patients. Several postmortem case reports have described the fatal outcome of patients when this abnormality was unrecognized. The incidence of anomalous coronary arteries is $1 \%$ to $2 \%$ in all patients undergoing cardiac catheterization. ${ }^{1,2}$ It would seem reasonable to consider performing coronary angiography on all patients regardless of age who require aortic valve replacement to clearly identify a coronary anomaly and thereby avoid a potentially catastrophic outcome in younger patients.

Recognizing the anatomy of this particular anomaly allowed proper identification of this vessel along the aortic anulus and therefore adequate mobilization, thereby avoiding the potential injury to this vessel when placing annular sutures. Several case reports have also described compression of this vessel when a large aortic valve prosthesis was inserted by compression within the atrioventricular groove against a calcified mitral anulus or a mitral prosthesis. ${ }^{1,3,4}$ Our patient did not have mitral calcification or a mitral prosthesis; how- 


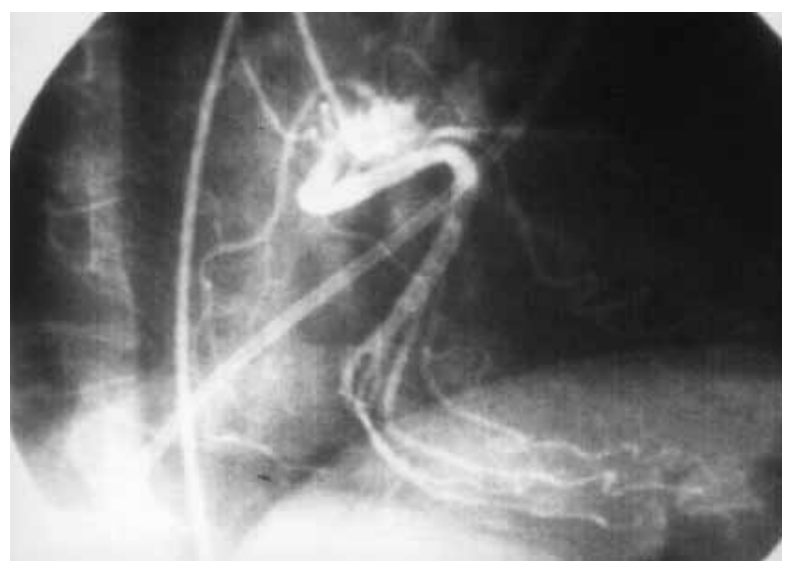

Fig 1. Coronary angiography demonstrating the origin of the anomalous left circumflex coronary artery from the right coronary cusp and its course about the aortic anulus.

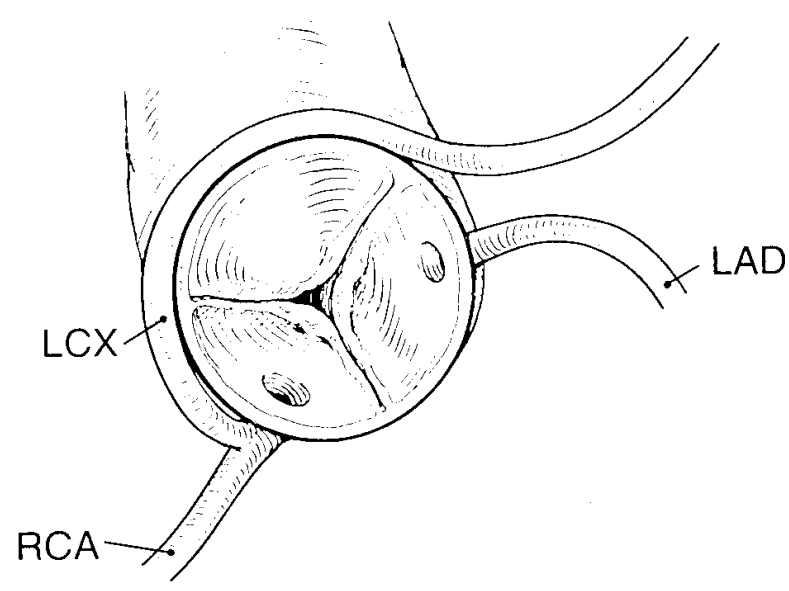

Fig 2. Anomalous left circumflex coronary artery originating from right coronary ostia. $L C X$, Left circumflex artery; $R C A$, right coronary artery; $L A D$, left anterior descending artery.

ever, we had to place a small aortic prosthesis because the aortic root was small.

Another potential advantage of identifying this anomaly in patients by means of preoperative coronary angiography is determining cardioplegia administration to ensure complete heart cardioplegia when direct manipulation of the coronary ostia is necessary.

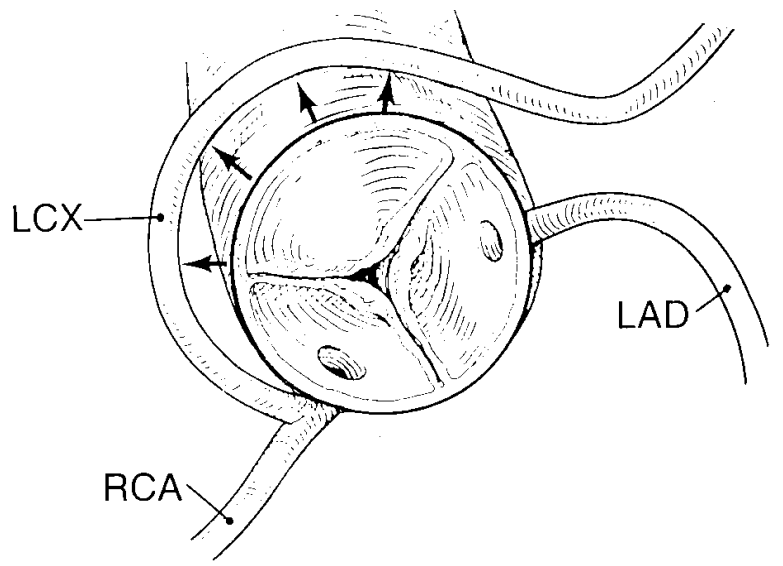

Fig 3. Dissection of anomalous left circumflex coronary artery away from aortic anulus to enable safe placement of valve sutures. $L C X$, Left circumflex artery; $R C A$, right coronary artery; $L A D$, left anterior descending artery.

This case illustrates the importance of determining this anomaly preoperatively and the method of handling this anomalous vessel intraoperatively when aortic valve replacement is required. The importance of adequate mobilization of the anomalous coronary artery from the aortic anulus avoids injury by suture ligation, and the awareness of possible compression of the anomalous coronary artery within the atrioventricular groove in the presence of a calcified mitral anulus or mitral prosthesis may influence the size of the aortic prosthesis inserted. Routine coronary angiography in young patients undergoing aortic valve replacement should be considered to identify anomalous coronary anatomy.

\section{REFERENCES}

1. Veinot JP, Acharya VC, Bedard P. Compression of anomalous circumflex coronary artery by a prosthetic valve ring. Ann Thorac Surg 1998;66:2093-4.

2. Page HL, Engel HJ, Campbell WB, Thomas CS. Anomalous origin of the left circumflex coronary artery. Circulation 1974;50:768-73.

3. Roberts WC, Morrow AG. Compression of anomalous left circumflex coronary arteries by prosthetic valve fixation rings. J Thorac Cardiovasc Surg 1969;6:834-8.

4. de Marchena EJ, Russo CD, Wozniak PM, Kessler KM. Compression of an anomalous left circumflex coronary artery by a bioprosthetic valve ring. J Cardiovasc Surg 1990;31:52-4. 